\title{
Produção e emprego industrial nos estados brasileiros: evidências de desindustrialização
}

Brazilian states manufacturing production and employment: evidences of deindustrialization

\author{
Iago Emidio Lutz de Souza (1) \\ Michele Polline Veríssimo (2) \\ (1) Universidade Federal de Uberlândia \\ (2) Universidade Federal de Uberlândia
}

\section{Abstract}

This paper investigates the deindustrialization hypothesis in Brazilian states in the period 1996-2014, and whether this process is linked to the economic policies (interest rate and trade liberalization) implemented in the country and to exchange rate and favorable prices context for primary products. For this, it analyzes manufacturing states production and employment indicators, and estimates panel data models. In general, manufacturing performance indicators signal a possible deindustrialization process in progress for some states. Moreover, the econometric results suggest the relevance of exchange rate and commodity prices to explain the lower capacity of the states manufacturing industry to generate output and employment, supporting deindustrialization hypothesis by Dutch disease.

\section{Keywords}

deindustrialization; value added; employment; Brazilian states; panel data.

JEL Codes L60; O14; R19.

\section{Resumo}

Este artigo investiga a hipótese de desindustrialização nos estados brasileiros no periodo 1996 2014 e se o processo está atrelado às políticas econômicas (taxa de juros e abertura comercial) implementadas no país e ao contexto cambial $e$ de preços favoráveis aos produtos primários. Para isso, analisa indicadores de produção e de emprego da indústria de transformação dos estados e estima modelos com dados em painel. Em sintese, os indicadores de desempenho industrial sinalizam um possivel processo de desindustrialização em curso para alguns estados. Ademais, os resultados econométricos sugerem a relevância do contexto cambial e dos preços das commodities para explicar a menor capacidade da indústria de transformação estadual em gerar produto e emprego, evidenciando a hipótese de desindustrialização via doença holandesa.

\section{Palavras-chave}

desindustrialização; valor adicionado; emprego; estados brasileiros; painel.

Códigos JEL L60; O14; R19. 


\section{Introdução}

A relação entre industrialização e crescimento tem recebido bastante atenção na literatura econômica. Kaldor (1966), por exemplo, considera que a indústria trabalha como o motor do crescimento, visto que a atividade industrial promove efeitos de encadeamento produtivos e tecnológicos com outros setores da economia.

O processo de industrialização brasileiro, a partir dos anos de 1950, promoveu mudança na estrutura produtiva, com ganho de relevância da indústria na economia em conjunto ao setor de serviços. Porém, ao longo dos últimos vinte anos, o país passou a lidar com uma perda de dinamismo do setor industrial, em parte relacionada ao contexto da estabilização econômica na década de 1990 (abertura comercial, âncora cambial e altas taxas de juros). Somam-se a isso eventos posteriormente observados nos anos 2000 (apreciação cambial e elevados preços internacionais de commodities), os quais tenderam a favorecer a especialização produtiva e exportadora em produtos básicos e semielaborados, suscitando o debate sobre desindustrialização no Brasil.

Em termos gerais, a desindustrialização pode ser entendida como redução da capacidade industrial em gerar produto e emprego em dada região. Esse problema pode estar atrelado ao processo de desenvolvimento econômico, em que a indústria perde participação relativa no produto e no emprego em decorrência do avanço da renda per capita, conforme apontam Rowthorn e Ramaswamy (1997). Pode relacionar-se ao conjunto de políticas liberalizantes implementadas em diversas economias, especialmente nos países latino-americanos, a partir dos anos de 1990, segundo Palma (2005) e Cano (2012). Ou pode ser decorrente da chamada "doença holandesa", em que o contexto de preços internacionais elevados das commodities promove apreciação cambial, prejudicando a rentabilidade das exportações de manufaturados, conforme os argumentos de Bresser-Pereira e Marconi (2008).

A discussão sobre a perda da relevância industrial também se estende ao campo dos estados brasileiros. Estudos como os de Saboia (2001), Cruz e Santos (2011), Botelho et al. (2014) e Monteiro e Lima (2017), entre outros, sugerem que há um processo de desindustrialização em curso no país, com efeitos mais visíveis na região Sudeste. Ainda, há a constatação de que possa estar ocorrendo desconcentração da atividade industrial, que estaria migrando do Centro-Sul para as regiões Nordeste e Centro-Oeste. 
Embora se reconheça que os diversos estados brasileiros possuem características específicas quanto ao comportamento da indústria de transformação, ensejando processos de desindustrialização com causas distintas, este artigo pretende analisar a ocorrência desse problema e seus possíveis fatores explicativos conforme aponta a literatura ligada aos pressupostos da doença holandesa e do conjunto de políticas econômicas vigentes no país. Desse modo, parte-se da hipótese preliminar de que o contexto cambial, dos preços favoráveis às commodities, de abertura comercial e da taxa de juros foi adverso ao desempenho industrial dos estados, com a atividade de transformação perdendo importância na geração de produto e emprego.

O debate sobre desindustrialização no Brasil tem avançado muito nos últimos anos, embora sem consenso entre os acadêmicos da área. Em discussões regionais, os estudos existentes, na maior parte, analisam o perfil industrial estados individualmente por meio de diversos indicadores e constatam a existência do problema para alguns deles. Porém, a literatura pertinente não avança no tratamento empírico do tema, o que abre espaço para uma análise econométrica mais aprofundada.

Assim, a principal contribuição deste estudo consiste na estimação de modelos com dados em painel para os estados brasileiros no período 19962014, que buscam explicar o desempenho da indústria de transformação no produto e emprego segundo os principais condicionantes apontados pela literatura (anteriormente citados). Tal metodologia, apesar de não captar as especificidades da desindustrialização em cada estado, sinaliza um comportamento geral de todos eles frente às variáveis relacionadas e o reflexo desse resultado sobre o contexto nacional.

Além desta introdução, a segunda seção do artigo conceitua o tema e explora algumas evidências regionais. A terceira seção apresenta indicadores do desempenho industrial dos estados brasileiros. A quarta seção descreve os aspectos metodológicos. A quinta seção discute os resultados. A sexta seção expõe as considerações finais.

\section{Revisão da literatura}

\subsection{Conceitos de desindustrialização}

A importância do setor industrial para o crescimento econômico é especial- 
mente enfatizada por Kaldor (1966). Para ele, o crescimento ocorre quando os fatores produtivos de setores com retornos decrescentes (agricultura) se transferem para setores com retornos crescentes (indústria), aumentando a produtividade de toda a economia e promovendo taxas de crescimento do produto sustentadas ao longo do tempo.

As conhecidas Leis de Kaldor explicam as diferentes performances de crescimento, postulando que: a) existe uma relação positiva entre o crescimento da indústria e o crescimento do produto agregado; $b$ ) existe uma relação positiva entre a taxa de crescimento da produtividade na indústria e o crescimento do produto industrial; c) quanto maior a taxa de crescimento das exportações industriais, maior o crescimento do produto; e d) o crescimento no longo prazo é determinado pela demanda agregada, de forma que a principal restrição ao crescimento do produto numa economia aberta é o Balanço de Pagamentos (Oreiro; Feijó, 2010).

Dessa forma, as exportações de manufaturados apresentam papel de destaque no dinamismo econômico no longo prazo, induzindo o crescimento do produto e também gerando divisas para aliviar a restrição externa ao Balanço de Pagamentos. Kaldor (1966) aponta que o crescimento depende da aceleração da taxa de crescimento das exportações nos setores em que a demanda é crescente, ou seja, de bens manufaturados, pois estes apresentam maior produtividade, retornos crescentes de escala e efeitos de encadeamento com os outros setores da economia.

Em linhas gerais, as etapas do desenvolvimento em que ocorre a transformação da economia estão intimamente ligadas às etapas de intensificação industrial. Contudo, quando a indústria atinge o auge da sua maturidade, com estrutura diversificada e intensa urbanização, a expansão do setor de serviços é natural, superando os resultados dos outros setores, inclusive da indústria. Tal processo é definido por Rowthorn e Wells (1987) como desindustrialização "positiva" (ou "natural"), observando-se redução da participação das atividades industriais no emprego e aumento do peso dos serviços à medida que a renda per capita atinge patamares mais elevados. Isso ocorre, sobretudo, pela mudança na elasticidade-renda da demanda por produtos industrializados, em que, com o aumento da renda, eleva-se a demanda por serviços, levando à perda relativa de participação da indústria no emprego. Ainda, a atividade terciária absorve a mão de obra liberada com o aumento da produtividade e as mudanças tecnológicas no setor industrial. 
Porém, nos países em desenvolvimento, a desindustrialização pode ocorrer quando a indústria ainda não está completamente formada ou em patamares de renda inferiores aos observados nos países desenvolvidos. Ou seja, pode ocorrer de forma precoce, como resultado de uma política cambial valorizada, de alterações na estrutura do comércio internacional, de elevadas taxas de juros, da mudança da estratégia de substituição de importações, entre outros. Essa forma de desindustrialização é vista por Rowthorn e Wells (1987) como "negativa", com a indústria perdendo participação nos resultados econômicos em contexto favorável aos setores primários. Nesses termos, há especialização da estrutura produtiva e exportadora em setores que apresentam vantagens comparativas estáticas, em suma, bens primários ou setores produtores de manufaturas de baixo valor adicionado ou conteúdo tecnológico, com efeitos negativos sobre o crescimento no longo prazo (Carvalho; Kupfer, 2007; Oreiro; Feijó, 2010).

Um dos conceitos mais utilizados na literatura para tratar da desindustrialização é o desenvolvido por Rowthorn e Ramaswany (1997), no qual o processo é entendido como uma redução da participação industrial no emprego total. Tregenna (2009), entretanto, amplia e define a desindustrialização como uma situação onde a indústria perde participação tanto no emprego, quanto no produto. Dessa forma, segundo Oreiro e Feijó (2010), o problema não ocorre somente quando a indústria está estagnada ou reduzindo (em termos absolutos), mas quando o setor perde importância na geração de emprego e/ou valor adicionado perante outros setores da economia.

A literatura explora diversos condicionantes do processo de desindustrialização. Palma (2005), por exemplo, descreve quatro possíveis fatores. O primeiro, conforme já discutido, trata do declínio no emprego industrial quando os países atingem certo nível de renda per capita ("U invertido") devido ao processo "natural" de desenvolvimento econômico. O segundo se refere ao contínuo declínio ao longo do tempo da relação de "U invertido" em países com renda média e alta em função das mudanças no paradigma tecnológico, da realocação de parte do processo de produção (intensivo em mão de obra) para países em desenvolvimento e das políticas econômicas implementadas. $\bigcirc$ terceiro diz respeito ao declínio no nível da renda per capita no ponto de virada da regressão (turning point), onde o emprego industrial é máximo, com os países em desenvolvimento reduzindo o emprego industrial em níveis mais baixos de renda per capita do que nos países desenvolvidos (desindustrialização precoce). 
Por fim, o último fator tratado por Palma (2005), que também é explorado por Bresser-Pereira (2007) e Bresser-Pereira e Marconi (2008), é o de desindustrialização ligada à doença holandesa. Nesse caso, a posse de recursos naturais abundantes que geram vantagens comparativas induz à especialização na produção de bens primários. A venda desses produtos promove a entrada de divisas, que aprecia o câmbio e prejudica a competitividade internacional dos bens industriais, visto a ausência de vantagens de custos. Com isso, tais produtos perdem participação na pauta exportadora levando a desindustrialização.

Palma (2005) destaca que, nos países latino-americanos, a perda de importância da atividade industrial no emprego pode ser explicada pelo conjunto de políticas econômicas liberalizantes (abertura comercial e financeira) implementadas nos anos de 1990 para promover a estabilidade macroeconômica. Tais políticas contribuíram para a reversão do processo de substituição de importações e levaram as economias a retrocederem ao padrão de especialização ricardiano em atividades intensivas em recursos naturais. Nesse caso, entende-se que a desindustrialização é "negativa", pois envolve reprimarização da economia.

Portanto, observa-se que a desindustrialização, ocorrendo de forma "natural", promove feedbacks positivos, com nível de renda mais elevado, expansão dos serviços e melhores empregos. Todavia, a desindustrialização "negativa", pela reprimarização da economia, pode gerar efeitos perversos. Com isso, este estudo busca evidências de um processo de desindustrialização em curso nos estados brasileiros sob essa última perspectiva.

\subsection{Evidências para os estados brasileiros}

Embora não exista consenso sobre a ocorrência de desindustrialização no Brasil, alguns trabalhos procuram avaliar as mudanças na estrutura produtiva nacional com base em análises regionais. Nestes termos, é possível encontrar duas linhas de estudos. A primeira foca na discussão da dinâmica industrial das regiões geográficas. Nesse sentido, Saboia (2001) verifica que, apesar da redução do emprego industrial no país, os estados das regiões Sul e Centro-Oeste receberam novas empresas industriais, com forte crescimento do emprego. Cruz e Santos (2011) analisam microrregiões industriais (até 5 mil empregos), e observam desconcentração das regiões 
metropolitanas de São Paulo e do Rio de Janeiro para o Centro-Oeste e Sul (Paraná e Santa Catarina), com as microrregiões do Sudeste (sobretudo São Paulo) se especializando em indústrias de maior conteúdo tecnológico. Botelho et al. (2014) analisam indicadores industriais das regiões brasileiras, e identificam ocorrência de desindustrialização, embora a indústria permaneça centrada no Centro-Sul do país. Monteiro e Lima (2017) também observam desconcentração regional do valor adicionado (VA) industrial, com indícios de desindustrialização no Nordeste, Sul e Sudeste, especialmente nas indústrias tradicionais. Ainda, identificam a precocidade da desindustrialização no Nordeste, que ocorre em níveis de renda per capita inferiores às das regiões Sul e Sudeste.

Uma segunda linha de trabalhos se dedica à análise particular da indústria dos diversos estados brasileiros. No caso de São Paulo, Ferreira (2003) argumenta que a perda de participação do emprego industrial relativamente ao setor de serviços é justificada pelo aumento do setor informal e pela precarização do trabalho, não se identificando desindustrialização, mas um movimento de desconcentração industrial da capital para o interior ou para outros estados. Já Rezende e Santos (2007) concluem que há desindustrialização no $\mathrm{ABC}$ paulista pela redução do emprego, visto que as empresas buscaram outras regiões para implementar suas plantas industriais visando diminuir custos de produção.

Caçador e Grassi (2009), ao analisarem o estado do Espírito Santo, constatam a especialização na produção de commodities, o que pode agravar a perda de dinamismo no futuro, quando se atingirem os limites da expansão destas. Em linha, Magalhães e Toscano (2011) apontam que o estado ampliou a participação das exportações de produtos básicos na pauta comercial brasileira entre 2000-2010, com perda expressiva de participação da indústria de baixa e média tecnologia. Tais evidências indicam que o estado colaborou para a apreciação artificial do câmbio decorrente da venda de bens primários indicada pela literatura da doença holandesa.

Sobre o estado de Minas Gerais, Sousa e Cardozo (2013) constatam que o PIB mineiro esteve atrelado à atividade industrial nos anos 2000 decorrente do avanço do setor de extração de minerais metálicos. Almeida e Souza (2014) também identificam ganho de participação absoluta do estado no Valor de Transformação Industrial (VTI) nacional no período 19602010, com destaque para a indústria química de fertilizantes, moveleira, fabricação de materiais elétricos e de comunicação e material de trans- 
portes. Avaliando as causas da desindustrialização em Minas Gerais nos anos 2000, Veríssimo e Araújo (2016) evidenciam o avanço da atividade extrativa, sendo que apenas a indústria de transformação foi negativamente afetada pelo contexto cambial desfavorável (apreciado), pela abertura comercial e pelas taxas de juros elevadas.

Sobral (2013) obtém evidências de desindustrialização no Rio de Janeiro, com risco de especialização estrutural e reprimarização da pauta exportadora. Rosendo e Britto (2011) seguem a mesma linha e afirmam que, apesar da observação de uma expansão do VTI no estado, a indústria fluminense lida com deterioração da estrutura industrial, tendo em vista a especialização nas atividades petrolíferas.

Em análise para o estado de Goiás, Arriel e Castro (2010) verificam que a participação da indústria no PIB estadual apresenta trajetória crescente, superando a média nacional, em decorrência das políticas de fomento à atividade produtiva (incentivos fiscais). Apesar de a indústria goiana ainda ser baseada em setores intensivos em recursos naturais, sobretudo, agropecuário, observa-se o surgimento de setores fármaco-químico e metal-mecânico.

No caso de Santa Catarina, Teixeira e Rodolfo (2012) estabelecem que a indústria, apesar de ser diversificada, foi afetada pela estagnação observada no mercado interno, sendo que alguns setores exportadores foram prejudicados pela crise internacional. Cario et al. (2013) identificam desindustrialização relativa no estado, com perda de participação gradativa da indústria de determinados setores na atividade econômica. Já Cavalieri et al. (2013) argumentam que, nas décadas de 1990 e 2000, a atividade industrial apresentou baixo crescimento, o que se deve às políticas pouco atrativas de investimento produtivo, reduzindo a produção e o emprego industrial.

Para o estado do Paraná, os trabalhos de Wasques (2012) e Scatolin et al. (2007) não constatam redução do peso da indústria no emprego total no período 1996-2010 e verificam aumento das exportações de bens de alta e média-alta tecnologia, refutando a possibilidade de reprimarização da pauta exportadora. Barbosa et al. (2015), ao analisarem o período 1996-2012, não corroboram a hipótese de desindustrialização paranaense, dado que várias microrregiões tiveram taxas positivas de crescimento da participação do emprego e do VA industrial.

Castilhos et al. (2010) observam que a indústria do Rio Grande do Sul mantém suas bases agrícolas e, apesar da entrada de investimentos diretos estrangeiros, não houve ampliação do parque industrial. Os autores ressal- 
tam a redução na participação industrial no VA do estado no período 19962007 devido ao aumento dos preços das commodities agrícolas e à redução da produtividade industrial.

O Quadro 1 sumariza os resultados obtidos pela literatura analisada.

Quadro 1 Síntese dos trabalhos analisados

\begin{tabular}{l|l|l}
\hline Autores & Amostra & $\begin{array}{l}\text { Evidências de } \\
\text { Desindustrialização }\end{array}$ \\
\hline Cruz e Santos (2011) & Sul e Sudeste & Sim \\
\hline Botelho et al. (2014) & Estados & Sim \\
\hline Monteiro e Lima (2017) & Regiões & Sim \\
\hline Ferreira (2003) & São Paulo & Não \\
\hline Rezende e Santos (2007) & ABC paulista & Sim \\
\hline Caçador e Grassi (2009) & Espírito Santo & Sim \\
\hline Magalhães e Toscano (2011) & Espírito Santo & Sim \\
\hline Sousa e Cardozo (2013) & Minas Gerais & Não se pode afirmar \\
\hline Almeida e Souza (2014) & Minas Gerais & Não se pode afirmar \\
\hline Veríssimo e Araújo (2016) & Minas Gerais & Sim \\
\hline Sobral (2013) & Rio de Janeiro & Sim \\
\hline Rosendo e Britto (2011) & Rio de Janeiro & Sim \\
\hline Arriel e Castro (2010) & Goiás & Não \\
\hline Teixeira e Rodolfo (2012) & Santa Catarina & Sim \\
\hline Cario et al. (2013) & Santa Catarina & Sim \\
\hline Cavalieri et al. (2013) & Santa Catarina & Sim \\
\hline Wasques (2012) & Paraná & Não \\
\hline Scatolin et al. (2007) & Paraná & Não \\
\hline Barbosa et al. (2015) & Paraná & Não \\
\hline Castilhos et al. (2010) & Rio Grande do Sul & Não se pode afirmar \\
\hline
\end{tabular}

Fonte: Elaboração própria.

Como visto, tais resultados estão sujeitos ao estado analisado, mas, em linhas gerais, reforçam o argumento de que a atividade industrial no Brasil e em suas Unidades Federativas está se modificando. Todavia, alguns estados podem não estar se desindustrializando, sendo que inexistem estudos para alguns dos estados brasileiros. Destarte, é relevante analisar indicadores industriais dos estados, de modo a se observarem quais parques produtivos estão de fato diminuindo. 


\section{Indicadores industriais dos estados brasileiros}

A Tabela 1 ilustra a participação do valor adicionado (VA) pelos setores da atividade econômica - agropecuária; indústria geral (transformação e extrativa); serviços; administração, saúde e educação públicas e seguridade social (chamados de "outros serviços") - no PIB de cada estado no período 1999-2012. ${ }^{1}$

Os dados revelam que, para o Brasil, as participações setoriais no PIB se mantêm relativamente estáveis (ganhos ou perdas inferiores a 1,5 p.p.). Todavia, a análise desagregada por estados indica situações diferentes. A agropecuária perde contribuição nos PIBs regionais (exceto no Centro-Oeste), com destaque para os estados de Tocantins (-12,71 p.p.) e Espírito Santo (-6,99 p.p.). Já a indústria ganha peso no Norte, Nordeste, Sudeste e Centro-Oeste. Cabe advertir que tais valores englobam os resultados da indústria extrativa, que é beneficiada pelo contexto de preços e de demanda externa favorável às commodities vigentes a partir de 2002. Assim, por exemplo, há significativo aumento de relevância da indústria geral no PIB no Tocantins (15,05 p.p.) e no Pará (11,77 p.p.), além de Rio de Janeiro (11,2 p.p.) e do Espírito Santo (10,7 p.p.), sendo os dois últimos bastante influenciados pelas atividades de exploração de petróleo. Em termos negativos, destaca-se o caso de São Paulo, berço da indústria de transformação brasileira, que perde 5,33 p.p. de participação no PIB do estado.

Tabela 1 Participação do VA setorial no PIB dos estados brasileiros, 1999/2012, em \%

\begin{tabular}{|c|c|c|c|c|c|c|c|c|c|c|c|c|}
\hline & \multicolumn{3}{|c|}{ Agropecuária } & \multicolumn{3}{|c|}{ Indústria } & \multicolumn{3}{|c|}{ Serviços } & \multicolumn{3}{|c|}{ Outros serviços* } \\
\hline & 1999 & 2012 & $\begin{array}{r}\Delta \\
(2012- \\
-1999)\end{array}$ & 1999 & 2012 & $\begin{array}{r}\Delta \\
(2012- \\
-1999)\end{array}$ & 1999 & 2012 & $\begin{array}{r}\Delta \\
(2012- \\
-1999)\end{array}$ & 1999 & 2012 & $\begin{array}{r}\Delta \\
(2012- \\
-1999)\end{array}$ \\
\hline RO & 19,03 & 20,51 & 1,48 & 10,35 & 18,25 & 7,90 & 36,21 & 32,75 & $-3,46$ & 34,42 & 28,49 & $-5,93$ \\
\hline$A C$ & 14,17 & 18,28 & 4,11 & 9,47 & 11,87 & 2,40 & 39,00 & 33,67 & $-5,33$ & 37,36 & 36,18 & $-1,18$ \\
\hline AM & 3,79 & 7,37 & 3,58 & 36,91 & 36,72 & $-0,20$ & 41,58 & 37,15 & $-4,43$ & 17,71 & 18,76 & 1,05 \\
\hline RR & 7,83 & 4,72 & $-3,11$ & 13,26 & 11,20 & $-2,06$ & 32,65 & 33,42 & 0,78 & 46,26 & 50,65 & 4,40 \\
\hline PA & 11,91 & 7,22 & $-4,69$ & 25,79 & 37,56 & 11,77 & 43,80 & 36,46 & $-7,34$ & 18,50 & 18,76 & 0,26 \\
\hline AP & 3,66 & 3,25 & $-0,41$ & 13,30 & 10,83 & $-2,47$ & 36,28 & 38,65 & 2,37 & 46,75 & 47,27 & 0,51 \\
\hline TO & 29,04 & 16,33 & $-12,71$ & 4,18 & 19,23 & 15,05 & 39,88 & 35,06 & $-4,82$ & 26,91 & 29,39 & 2,48 \\
\hline
\end{tabular}

(continua)

1 Conforme disponibilidade de dados do IBGE, tendo em vista a mudança do ano de referência do cálculo do produto em 2010. 
Tabela 1 (continuação)

\begin{tabular}{|c|c|c|c|c|c|c|c|c|c|c|c|c|}
\hline & \multicolumn{3}{|c|}{ Agropecuária } & \multicolumn{3}{|c|}{ Indústria } & \multicolumn{3}{|c|}{ Serviços } & \multicolumn{3}{|c|}{ Outros serviços* } \\
\hline & 1999 & 2012 & $\begin{array}{r}\Delta \\
(2012- \\
-1999)\end{array}$ & 1999 & 2012 & $\begin{array}{r}\Delta \\
(2012- \\
-1999)\end{array}$ & 1999 & 2012 & $\begin{array}{r}\Delta \\
(2012- \\
-1999)\end{array}$ & 1999 & 2012 & $\begin{array}{r}\Delta \\
(2012- \\
-1999)\end{array}$ \\
\hline $\mathbf{N}$ & 12,77 & 11,10 & $-1,68$ & 16,18 & 20,81 & 4,63 & 38,49 & 35,31 & $-3,18$ & 32,56 & 32,79 & 0,23 \\
\hline MA & 15,84 & 14,98 & $-0,86$ & 16,65 & 16,58 & $-0,07$ & 46,79 & 47,01 & 0,22 & 20,72 & 21,43 & 0,71 \\
\hline $\mathrm{PI}$ & 10,64 & 4,20 & $-6,44$ & 14,48 & 18,65 & 4,16 & 47,91 & 48,10 & 0,19 & 26,98 & 29,06 & 2,08 \\
\hline CE & 7,28 & 3,38 & $-3,90$ & 24,53 & 22,84 & $-1,69$ & 49,77 & 51,51 & 1,74 & 18,43 & 22,27 & 3,84 \\
\hline RN & 3,53 & 3,40 & $-0,13$ & 22,85 & 23,88 & 1,03 & 45,94 & 45,07 & $-0,87$ & 27,67 & 27,65 & $-0,02$ \\
\hline PB & 7,79 & 3,59 & $-4,19$ & 19,08 & 22,75 & 3,68 & 43,26 & 41,98 & $-1,28$ & 29,88 & 31,68 & 1,80 \\
\hline $\mathrm{PE}$ & 3,73 & 2,70 & $-1,03$ & 22,50 & 25,12 & 2,62 & 50,22 & 49,08 & $-1,14$ & 23,55 & 23,10 & $-0,45$ \\
\hline AL & 12,46 & 5,62 & $-6,84$ & 24,21 & 22,24 & $-1,97$ & 40,15 & 45,81 & 5,66 & 23,18 & 26,33 & 3,15 \\
\hline SE & 5,18 & 4,21 & $-0,97$ & 25,20 & 28,88 & 3,68 & 45,76 & 39,93 & $-5,83$ & 23,85 & 26,98 & 3,13 \\
\hline BA & 7,27 & 7,34 & 0,07 & 27,19 & 25,48 & $-1,71$ & 49,92 & 48,38 & $-1,54$ & 15,62 & 18,80 & 3,18 \\
\hline NE & 8,19 & 5,49 & $-2,70$ & 21,85 & 22,94 & 1,08 & 46,64 & 46,32 & $-0,32$ & 23,32 & 25,25 & 1,94 \\
\hline$M G$ & 11,26 & 8,59 & $-2,67$ & 28,86 & 29,37 & 0,51 & 46,36 & 48,06 & 1,71 & 13,53 & 13,98 & 0,45 \\
\hline ES & 12,94 & 5,95 & $-6,99$ & 28,49 & 39,19 & 10,70 & 42,53 & 41,19 & $-1,34$ & 16,04 & 13,66 & $-2,38$ \\
\hline RJ & 0,62 & 0,43 & $-0,19$ & 20,99 & 32,19 & 11,20 & 59,38 & 49,45 & $-9,93$ & 19,01 & 17,93 & $-1,09$ \\
\hline SP & 1,57 & 1,89 & 0,32 & 30,32 & 24,99 & $-5,33$ & 60,06 & 63,62 & 3,56 & 8,05 & 9,50 & 1,45 \\
\hline SE & 6,60 & 4,22 & $-2,38$ & 27,16 & 31,43 & 4,27 & 52,08 & 50,58 & $-1,50$ & 14,16 & 13,77 & $-0,39$ \\
\hline PR & 9,33 & 9,22 & $-0,10$ & 27,74 & 24,54 & $-3,20$ & 52,56 & 53,92 & 1,36 & 10,38 & 12,32 & 1,95 \\
\hline SC & 8,51 & 4,27 & $-4,24$ & 33,23 & 33,67 & 0,44 & 47,18 & 49,48 & 2,30 & 11,08 & 12,58 & 1,50 \\
\hline RS & 8,85 & 8,44 & $-0,41$ & 27,01 & 25,21 & $-1,80$ & 51,81 & 49,26 & $-2,54$ & 12,33 & 17,08 & 4,75 \\
\hline$S$ & 8,89 & 7,31 & $-1,58$ & 29,33 & 27,81 & $-1,52$ & 50,52 & 50,89 & 0,37 & 11,26 & 14,00 & 2,73 \\
\hline MS & 20,43 & 15,44 & $-4,99$ & 17,43 & 21,69 & 4,26 & 44,33 & 43,98 & $-0,36$ & 17,81 & 18,89 & 1,08 \\
\hline MT & 23,03 & 28,55 & 5,52 & 17,25 & 15,79 & $-1,46$ & 41,97 & 41,69 & $-0,28$ & 17,75 & 13,97 & $-3,78$ \\
\hline GO & 12,46 & 13,17 & 0,71 & 21,87 & 26,28 & 4,41 & 50,67 & 46,75 & $-3,92$ & 15,00 & 13,79 & $-1,21$ \\
\hline DF & 0,23 & 0,34 & 0,11 & 5,25 & 5,66 & 0,41 & 44,14 & 38,76 & $-5,37$ & 50,38 & 55,23 & 4,85 \\
\hline $\mathrm{CO}$ & 14,04 & 14,38 & 0,34 & 15,45 & 17,36 & 1,91 & 45,28 & 42,79 & $-2,48$ & 25,24 & 25,47 & 0,23 \\
\hline Brasil & 5,47 & 5,32 & $-0,15$ & 25,95 & 26,02 & 0,07 & 53,33 & 52,06 & $-1,28$ & 15,25 & 16,60 & 1,36 \\
\hline
\end{tabular}

Fonte: IBGE.

*Administração, saúde e educação públicas e seguridade social.

Os serviços passam a colaborar menos com os PIBs regionais, exceto no Sul. Nos estados de Amapá, Alagoas, Ceará, e, sobretudo, em São Paulo e no Paraná, a perda da participação industrial no PIB é acompanhada pelo 
aumento da contribuição dos serviços. Assim, para tais estados não é possível refutar a hipótese de desindustrialização "natural". Vale ressaltar o aumento da participação dos serviços associados à administração, saúde e educação públicas e seguridade social nas regiões (exceto Sudeste), com ênfase no Distrito Federal (4,85 p.p.) e Rio Grande do Sul (4,75 p.p.).

A Tabela 2 sistematiza os dois indicadores tradicionalmente utilizados pela literatura para se avaliar desindustrialização, conforme Rowthorn e Ramaswamy (1997) e Tregenna (2009) - a participação da indústria de transformação no produto (VTI/PIB) e no emprego total - entre 1996 e 2014.

Para o Brasil, verifica-se que a indústria de transformação mantém participação estável no produto (VTI/PIB), com ganho de 0,33 p.p., mas perde importância na geração de emprego (-3,65 p.p.). A participação do VTI no PIB aumenta em boa parte dos estados, embora, para alguns deles, a mudança seja pouco significativa, como em Roraima, Pernambuco e Distrito Federal (menos de 1 p.p.). Em outros, observa-se maior salto, como nos estados das regiões Sul e Centro-Oeste (exceto Distrito Federal), além da Bahia, no Nordeste. Em contraponto, alguns estados tiveram quedas expressivas do indicador, como em Alagoas (8,15 p.p.). Destaca-se a região Sudeste, notadamente São Paulo, cuja indústria de transformação perde 3,22 p.p. de capacidade em gerar produto.

Tabela 2 Produção e emprego da indústria de transformação, 1996/2014, em \%

\begin{tabular}{|c|c|c|c|c|c|c|}
\hline \multirow[b]{2}{*}{ UF } & \multicolumn{3}{|r|}{ VTI/PIB } & \multicolumn{3}{|c|}{ Emprego indústria / emprego total } \\
\hline & 1996 & 2014 & $\begin{array}{r}\Delta \\
(2014-1996)\end{array}$ & 1996 & 2014 & $\begin{array}{r}\Delta \\
(2014-1996)\end{array}$ \\
\hline RO & 2,76 & 7,76 & 4,99 & 10,56 & 10,32 & $-0,24$ \\
\hline AC & n.d. & 4,65 & n.d. & 4,38 & 5,00 & 0,61 \\
\hline AM & 42,19 & 46,89 & 4,70 & 25,94 & 20,56 & $-5,38$ \\
\hline RR & 0,33 & 1,15 & 0,82 & 4,23 & 3,56 & $-0,67$ \\
\hline PA & 8,14 & 6,79 & $-1,35$ & 12,57 & 8,06 & $-4,51$ \\
\hline AP & 2,76 & 4,97 & 2,21 & 4,78 & 2,89 & $-1,90$ \\
\hline TO & 1,66 & 6,18 & 4,51 & 5,00 & 6,72 & 1,72 \\
\hline $\mathbf{N}$ & 18,05 & 17,18 & $-0,86$ & 14,06 & 10,56 & $-3,51$ \\
\hline MA & 6,06 & 7,29 & 1,23 & 8,63 & 5,66 & $-2,98$ \\
\hline PI & 4,27 & 5,69 & 1,42 & 8,39 & 6,60 & $-1,79$ \\
\hline CE & 10,61 & 14,44 & 3,83 & 17,57 & 17,05 & $-0,52$ \\
\hline
\end{tabular}

(continua) 
Tabela 2 (continuação)

\begin{tabular}{|c|c|c|c|c|c|c|}
\hline \multirow[b]{2}{*}{ UF } & \multicolumn{3}{|r|}{ VTI/PIB } & \multicolumn{3}{|c|}{ Emprego indústria / emprego total } \\
\hline & 1996 & 2014 & $\begin{array}{r}\Delta \\
(2014-1996)\end{array}$ & 1996 & 2014 & $\begin{array}{r}\Delta \\
(2014-1996)\end{array}$ \\
\hline RN & 6,34 & 10,39 & 4,05 & 11,72 & 10,55 & $-1,17$ \\
\hline PB & 8,63 & 9,93 & 1,30 & 14,03 & 12,04 & $-1,99$ \\
\hline PE & 12,57 & 12,62 & 0,04 & 17,34 & 13,61 & $-3,73$ \\
\hline AL & 19,82 & 11,67 & $-8,15$ & 23,07 & 16,48 & $-6,59$ \\
\hline SE & 5,97 & 8,56 & 2,59 & 9,50 & 11,58 & 2,08 \\
\hline BA & 12,32 & 21,61 & 9,29 & 8,62 & 9,68 & 1,05 \\
\hline NE & 10,77 & 13,93 & 3,16 & 13,58 & 11,92 & $-1,66$ \\
\hline MG & 17,64 & 19,42 & 1,79 & 18,72 & 16,54 & $-2,18$ \\
\hline ES & 10,51 & 10,26 & $-0,26$ & 14,95 & 13,29 & $-1,66$ \\
\hline RJ & 13,20 & 11,81 & $-1,38$ & 13,45 & 10,22 & $-3,23$ \\
\hline SP & 25,63 & 22,41 & $-3,22$ & 25,97 & 19,38 & $-6,59$ \\
\hline SE & 21,55 & 19,10 & $-2,45$ & 21,71 & 16,84 & $-4,86$ \\
\hline PR & 17,29 & 26,74 & 9,45 & 20,96 & 22,20 & 1,24 \\
\hline SC & 23,70 & 28,71 & 5,02 & 35,81 & 30,09 & $-5,72$ \\
\hline RS & 20,71 & 24,95 & 4,24 & 27,53 & 23,50 & $-4,02$ \\
\hline $\mathbf{S}$ & 20,16 & 26,54 & 6,39 & 27,05 & 24,77 & $-2,28$ \\
\hline MS & 7,12 & 18,61 & 11,49 & 9,55 & 14,77 & 5,22 \\
\hline MT & 9,04 & 15,76 & 6,72 & 16,48 & 13,07 & $-3,42$ \\
\hline GO & 9,55 & 17,95 & 8,40 & 13,47 & 16,57 & 3,10 \\
\hline DF & 0,90 & 1,57 & 0,68 & 2,71 & 3,03 & 0,33 \\
\hline CO & 4,63 & 11,28 & 6,65 & 9,24 & 11,48 & 2,23 \\
\hline Brasil & 18,37 & 18,70 & 0,33 & 20,14 & 16,48 & $-3,65$ \\
\hline
\end{tabular}

Fonte: IBGE, RAIS.

No caso do emprego, a indústria de transformação ganha relevância apenas no Centro-Oeste, com variação positiva de 2,23 p.p. Nas demais regiões, boa parte dos estados perde capacidade da indústria em gerar empregos. Novamente, destacam-se os estados do Sudeste, em que a piora do indicador é evidente em todos os estados, especialmente em São Paulo, com queda de 6,59 p.p. Embora o indicador de emprego aluda à perda de dinamismo da indústria de transformação, este, por si só, não é suficiente para sinalizar desindustrialização, visto que pode ser afetado por mudanças tecnológicas ou de produtividade dos trabalhadores, o que poupa a 
contratação de mão de obra sem que isso represente perda de relevância da indústria no produto.

A Tabela 3 apresenta a participação dos produtos básicos, semimanufaturados e manufaturados nas exportações totais dos estados brasileiros entre 1996 e 2014. Para o Brasil, verifica-se avanço significativo dos produtos básicos (24,07 p.p.), enquanto os manufaturados perdem 19,83 p.p. de participação na pauta exportadora, sinalizando reprimarização da economia. Resultados semelhantes também são observados em boa parte dos estados, especialmente nos das regiões Sudeste (exceto Espírito Santo), Sul e Centro-Oeste. No Norte e Nordeste, há ganho de participação dos manufaturados na pauta em alguns estados, mas não o suficiente para influenciar o indicador nacional, pois os estados com desempenho positivo possuem baixa representatividade daqueles bens nas exportações. Em síntese, os dados assinalam perda de relevância da indústria de transformação frente aos produtos primários, com desindustrialização via doença holandesa, como discutido em Bresser-Pereira e Marconi (2008) e Oreiro e Feijó (2010).

Tabela 3 Exportações por fator agregado, 1996/2014, em \%

\begin{tabular}{l|r|rr|r|r|r|r|r|r}
\hline \multirow{2}{*}{ UF } & & & Básicos & \multicolumn{2}{|r|}{ Semimanufaturados } & \multicolumn{3}{|r}{ Manufaturados } \\
\cline { 2 - 12 } & $\mathbf{1 9 9 6}$ & $\mathbf{2 0 1 4}$ & $\begin{array}{r}\Delta \\
\mathbf{( 2 0 1 4 -} \\
\mathbf{- 1 9 9 6 )}\end{array}$ & $\mathbf{1 9 9 6}$ & $\mathbf{2 0 1 4}$ & $\begin{array}{r}\Delta \\
\mathbf{( 2 0 1 4 -} \\
\mathbf{- 1 9 9 6 )}\end{array}$ & $\mathbf{1 9 9 6}$ & $\mathbf{2 0 1 4}$ & $\begin{array}{r}\Delta \\
\mathbf{( 2 0 1 4 -} \\
\mathbf{- 1 9 9 6 )}\end{array}$ \\
\hline RO & 14,53 & 92,07 & 77,54 & 53,76 & 6,08 & $-47,69$ & 31,71 & 1,85 & $-29,86$ \\
\hline AC & 2,25 & 40,09 & 37,84 & 97,38 & 6,66 & $-90,73$ & $n, d$, & 53,25 & $n, d$ \\
\hline AM & 5,65 & 4,62 & $-1,03$ & 9,90 & 1,35 & $-8,54$ & 80,41 & 89,88 & 9,47 \\
\hline RR & 2,50 & 85,64 & 83,14 & 18,88 & 6,21 & $-12,68$ & 78,32 & 3,63 & $-74,69$ \\
\hline PA & 47,85 & 76,93 & 29,09 & 43,56 & 10,18 & $-33,38$ & 8,58 & 12,51 & 3,93 \\
\hline AP & 31,69 & 36,88 & 5,19 & 60,22 & 58,03 & $-2,19$ & 8,08 & 5,06 & $-3,03$ \\
\hline T0 & 51,06 & 98,02 & 46,96 & 44,21 & 1,91 & $-42,30$ & 4,73 & 0,07 & $-4,67$ \\
\hline N & 44,07 & 74,04 & 29,97 & 42,34 & 10,20 & $-32,15$ & 13,33 & 15,22 & 1,89 \\
\hline MA & 9,24 & 29,39 & 20,15 & 79,96 & 33,25 & $-46,71$ & 10,70 & 35,35 & 24,65 \\
\hline PI & 5,56 & 77,00 & 71,43 & 62,15 & 21,61 & $-40,54$ & 32,24 & 1,39 & $-30,85$ \\
\hline CE & 52,24 & 20,11 & $-32,13$ & 14,97 & 19,92 & 4,95 & 31,09 & 58,20 & 27,11 \\
\hline RN & 50,47 & 70,96 & 20,49 & 19,63 & 1,55 & $-18,08$ & 29,62 & 23,73 & $-5,89$ \\
\hline PB & 4,69 & 15,98 & 11,30 & 6,25 & 3,88 & $-2,37$ & 89,05 & 80,14 & $-8,91$ \\
\hline & & & & & & & & $($ continua)
\end{tabular}


Tabela 3 (continuação)

\begin{tabular}{|c|c|c|c|c|c|c|c|c|c|}
\hline \multirow[b]{2}{*}{ UF } & \multicolumn{3}{|r|}{ Básicos } & \multicolumn{3}{|c|}{ Semimanufaturados } & \multicolumn{3}{|c|}{ Manufaturados } \\
\hline & 1996 & 2014 & $\begin{array}{r}\Delta \\
(2014- \\
-1996)\end{array}$ & 1996 & 2014 & $\begin{array}{r}\Delta \\
(2014- \\
-1996)\end{array}$ & 1996 & 2014 & $\begin{array}{r}\Delta \\
(2014- \\
-1996)\end{array}$ \\
\hline PE & 6,29 & 14,52 & 8,23 & 35,17 & 11,14 & $-24,03$ & 56,66 & 69,13 & 12,47 \\
\hline$A L$ & 6,06 & 2,45 & $-3,61$ & 67,42 & 86,32 & 18,90 & 26,50 & 11,12 & $-15,38$ \\
\hline SE & 0,11 & 2,77 & 2,66 & $\mathrm{n}, \mathrm{d}$ & 4,06 & $n, d$ & 99,89 & 93,16 & $-6,73$ \\
\hline BA & 10,20 & 24,92 & 14,72 & 31,86 & 26,68 & $-5,18$ & 56,95 & 47,12 & $-9,83$ \\
\hline NE & 14,15 & 25,11 & 10,97 & 40,70 & 27,80 & $-12,90$ & 44,32 & 45,45 & 1,13 \\
\hline MG & 41,21 & 63,39 & 22,19 & 25,71 & 18,77 & $-6,94$ & 33,00 & 17,65 & $-15,35$ \\
\hline ES & 41,43 & 66,23 & 24,79 & 53,00 & 14,39 & $-38,61$ & 4,59 & 18,70 & 14,11 \\
\hline RJ & 2,06 & 57,95 & 55,89 & 7,08 & 9,02 & 1,93 & 81,13 & 28,88 & $-52,25$ \\
\hline SP & 6,23 & 12,89 & 6,66 & 8,31 & 12,27 & 3,96 & 84,40 & 69,39 & $-15,01$ \\
\hline SE & 16,75 & 40,26 & 23,50 & 16,10 & 13,51 & $-2,59$ & 65,69 & 42,89 & $-22,80$ \\
\hline PR & 49,02 & 50,85 & 1,83 & 13,58 & 11,98 & $-1,61$ & 36,81 & 35,63 & $-1,18$ \\
\hline SC & 34,64 & 46,31 & 11,67 & 4,47 & 2,73 & $-1,75$ & 60,86 & 50,90 & $-9,95$ \\
\hline RS & 31,75 & 52,57 & 20,82 & 12,29 & 6,81 & $-5,48$ & 55,58 & 39,38 & $-16,20$ \\
\hline $\mathbf{S}$ & 38,20 & 50,65 & 12,45 & 11,08 & 7,89 & $-3,19$ & 50,34 & 40,34 & $-9,99$ \\
\hline MS & 79,24 & 67,25 & $-11,99$ & 16,01 & 30,62 & 14,61 & 4,74 & 2,12 & $-2,62$ \\
\hline MT & 64,07 & 95,19 & 31,12 & 25,12 & 3,96 & $-21,16$ & 10,81 & 0,85 & $-9,96$ \\
\hline GO & 62,09 & 74,31 & 12,21 & 30,16 & 21,40 & $-8,76$ & 7,75 & 4,29 & $-3,46$ \\
\hline DF & 79,86 & 78,63 & $-1,24$ & 2,25 & 0,01 & $-2,24$ & 1,61 & 4,81 & 3,21 \\
\hline CO & 67,22 & 84,30 & 17,08 & 24,01 & 13,48 & $-10,53$ & 8,40 & 2,02 & $-6,38$ \\
\hline Brasil & 24,92 & 48,99 & 24,07 & 18,04 & 13,00 & $-5,04$ & 55,70 & 35,87 & $-19,83$ \\
\hline
\end{tabular}

Fonte: MDIC

Ainda que não se possa concluir sobre a ocorrência de desindustrialização com base na avaliação preliminar dos indicadores anteriores, é possível perceber mudanças no desempenho industrial, com ênfase nos estados da região Sudeste, os quais mais contribuem em termos relativos na geração de produto, emprego e exportações de manufaturados, mas também os que mais perdem participação nos referidos indicadores no período analisado. Embora tal processo não seja homogêneo entre as diversas Unidades da Federação, não se pode afirmar que as perdas da indústria de transformação do Sudeste foram compensadas pelos ganhos dos demais estados, de forma a neutralizar o problema da desindustrialização. Ademais, faz-se 
necessário explorar os determinantes do menor dinamismo industrial dos estados, o que é realizado na sequência deste artigo.

\section{Modelos e metodologia}

Este artigo investiga a hipótese de desindustrialização nos estados brasileiros conforme as causas apontadas pela literatura que associa o processo ao contexto da doença holandesa e das políticas econômicas implementadas no país.

Toma-se como base o conceito desenvolvido por Rowthorn e Ramaswamy (1997) e Tregenna (2009) de desindustrialização "negativa", em que ocorre perda de participação da atividade industrial (valor adicionado ou emprego) nos resultados econômicos em função do contexto favorável aos produtos primários (taxa de câmbio real e preços internacionais das commodities), como em Bresser-Pereira (2007) e Bresser-Pereira e Marconi (2008), ou de políticas econômicas liberalizantes (abertura comercial e elevadas taxas de juros), conforme Palma (2005) e Cano (2012). Tais fatores podem conduzir à especialização regressiva da estrutura produtiva da economia em bens primários em detrimento das atividades industriais.

A metodologia utilizada envolve a estimação de modelos com dados em painel, os quais consistem na combinação de dados em corte transversal (diferentes variáveis no mesmo tempo) com dados das séries temporais (mesma variável em tempos diferentes). Segundo Hsiao (2006), essa metodologia permite melhor investigação sobre a mudança das variáveis, considerando o efeito de variáveis não observadas.

Considera-se o seguinte modelo genérico de dados em painel para uma variável dependente (y):

$$
y_{i t}=\beta_{1} x_{i t 1}+\beta_{2} x_{i t 2}+\ldots+\beta_{k} x_{i t k}+\mu_{i}+\mu_{i t}
$$

onde $t=1,2, \ldots T$ (dimensão temporal) e $i=1,2, \ldots N$ (dimensão cross-section), $y$ é a variável dependente, $x$ é o conjunto de $k$ variáveis explicativas, $\mu_{i}$ são os efeitos fixos individuais, específicos de cada estado e invariantes no tempo, e $\mu_{i t}$ é o termo de erro.

$\bigcirc$ objetivo do modelo é obter estimadores consistentes de $\beta$, com eficiência, fazendo-se suposições sobre a correlação entre os termos aleatórios e os regressores, o que determina a não tendenciosidade dos parâmetros. 
Dois modelos básicos derivam da equação (1) e são denominados como modelos de painel estático. O primeiro deles é chamado de modelo de Efeitos Fixos (EF), e é utilizado quando se supõe que os efeitos individuais $\mu_{i}$ podem ser correlacionados com um ou mais regressores de $x$. A maneira correta de se estimar o modelo de EF é controlando tal correlação. Outra suposição é que a estimação por EF não tolera variáveis com características invariáveis ao longo do tempo, sendo aplicado quando as variáveis não observadas são correlacionadas com todas ou algumas das variáveis explicativas. Nesse caso, as estimativas por Mínimos Quadrados Ordinários (MOO) fornecem estimadores consistentes.

O segundo modelo é o de Efeitos Aleatórios (EA), o qual considera o termo $\mu_{i}$ como uma variável aleatória e não correlacionada com as variáveis explicativas. Dessa maneira:

$$
y_{i t}=\beta_{1} x_{i t 1}+\beta_{2} x_{i t 2}+\ldots+\beta_{k} x_{i t k}+w_{i t}
$$

onde: $w_{i t}=\mu_{i}+\mu_{i t}, \operatorname{com} \mu_{i t} \sim i i d\left(0, \sigma_{\mu}^{2}\right)$ e $w_{i t} \sim \operatorname{iid}\left(0, \sigma_{u}^{2}\right)$;

Esse modelo é utilizado quando os efeitos não observados forem não correlacionados com as variáveis explicativas, envolvendo a estimação por Mínimos Quadrados Generalizados (MQG). A informação para a escolha entre os modelos EF e EA é fornecida pelo teste de Hausman, cuja hipótese nula é de que os estimadores por EA são consistentes. ${ }^{2}$

Os modelos consideram como variáveis dependentes a participação da indústria de transformação em termos do valor adicionado no PIB (VA indústria) e também no emprego total (Emprego indústria) dos estados no período 1996-2014. A variável VA indústria foi construída dividindo o Valor da Transformação Industrial (VTI) pelo PIB a preços constantes (de 2010) de cada estado, extraídos do IBGE. A variável Emprego indústria foi obtida pela razão entre o emprego na indústria de transformação e o emprego total do estado, com dados da RAIS.

2 Os modelos EF e EA possuem algumas limitações, tais como a possível endogenia das variáveis explicativas, e a possibilidade de heterogeneidade e autocorrelação. O problema da endogenia normalmente é superado por meio das estimações dos modelos dinâmicos GMM (Método dos Momentos Generalizados). Porém, as estimações GMM (difference ou system) para os modelos aqui tratados não foram robustas devido ao excesso de instrumentos, mesmo após a utilização dos comandos laglimits ou collapse no Stata 13. Para corrigir os possiveis problemas de heterocedasticidade e autocorrelação, as estimações consideraram os erros-padrão robustos. 
O propósito da estimação econométrica é avaliar o sinal e a significância estatística dos coeficientes das variáveis explicativas, conforme aponta os trabalhos de Palma (2005), Bresser-Pereira e Marconi (2008), Oreiro e Feijó (2010), e Cano (2012), entre outros:

a) Taxa de câmbio real efetiva (TCREF), índice $2005=100$, construída para cada estado a partir da metodologia de Vieira et al. (2014). Na evidência de desindustrialização, espera-se que o sinal obtido seja positivo, isto é, a depreciação cambial é importante para estimular a inserção externa dos produtos manufaturados estaduais e alavancar a indústria de transformação.

b) Preço das commodities (IPCOM), índice $2005=100$. Tal variável (Fonte: FMI) consiste nos preços dos principais produtos exportados por cada estado. Na evidência de desindustrialização, espera-se um sinal negativo da variável, com os preços internacionais dos produtos primários favorecendo a rentabilidade desses bens em detrimento dos setores industriais, o que desestimula a atividade industrial.

c) Taxa de juros (JUROS), em \%. A variável (Fonte: BCB) consiste na taxa de juros Over-Selic mensal anualizada transformada para taxa real conforme o IPCA de cada ano. O sinal esperado é negativo, na medida em que os juros elevados inibem os investimentos na atividade produtiva.

d) Grau de abertura para produtos manufaturados (ABERT), em \%. A variável corresponde à soma das exportações e importações de produtos manufaturados estaduais (Fonte: MDIC) dividida pelo PIB estadual (Fonte: IBGE). Havendo desindustrialização, o sinal esperado é negativo, pois maior grau de abertura comercial pode implicar substituição de produção industrial interna por importações. Todavia, a abertura comercial pode afetar positivamente a indústria de transformação, tendo em vista a importação de insumos mais baratos, como matérias-primas industriais, máquinas e equipamentos.

Ainda, os modelos estimados incluem outras variáveis de controle, que são:

a) PIB estadual (PIBESTADUAL), correspondente ao PIB a preços de mercado corrente (em $\mathrm{R} \$ \mathrm{mil}$ ), com sinal esperado positivo. Tal variável objetiva mensurar o tamanho dos estados, sendo que estados com maior PIB tendem a ter um crescimento nas relações com as variáveis dependentes. 
b) Dummy PIB per capita (DPIBPERCAPITA). Foi atribuído valor 1 para estados com PIB per capita estaduais maiores do que o do Brasil, e zero para os estados com valores menores que o do Brasil. O objetivo é analisar o efeito renda, isto é, se estados com maior renda per capita (mais desenvolvidos) apresentam crescimento nas relações com as variáveis dependentes.

c) Dummy da crise de 2008 (DCRISE2008), sendo atribuído valor 1 para os anos de 2008 a 2014, e zero para os demais anos. O sinal esperado é negativo, dado que a crise em 2008 pode afetar o produto e o emprego nos estados brasileiros devido à instabilidade internacional.

d) Dummies temporais, de 1997 a 2014, com o intuito de controlar os efeitos das variáveis que só variam com o tempo, e não entre os estados.

Os modelos foram estimados com as variáveis (exceto dummies) em logaritmo natural, o que reduz a sensibilidade de observações desiguais devido ao estreitamento ocorrido na amplitude dos valores das variáveis, além de aliviar problemas de heterocedasticidade e de concentração em distribuições condicionais.

As estimações foram realizadas com a introdução de uma variável de interesse por vez, seguindo a ordem TCREF, IPCOM, JUROS e ABERT, a fim de avaliar as duas vias de desindustrialização que se pretende analisar. Primeiramente, a inclusão da variável TCREF explora a desindustrialização como causa de um processo de doença holandesa, o que pode ser corroborado (ou não) com a inclusão da variável IPCOM. A variável JUROS mostra se as políticas liberalizantes contribuem para a especialização regressiva da estrutura produtiva da economia, o que também pode ser confirmado ao se adicionar a variável ABERT.

\section{Análise dos resultados}

As Tabelas 4 e 5 sumarizam as evidências obtidas. Destaca-se que o Teste de Hausman demonstra que a estimação por Efeitos Aleatórios (EA) foi a especificação mais adequada em todos os modelos, revelando que os efeitos não observados são não correlacionados com as variáveis explicativas.

Os resultados da Tabela 4 para a variável dependente VA indústria apontam que a taxa de câmbio real efetiva (TCREF) apresenta o sinal positivo esperado, com significância estatística em todos os modelos. Os coeficientes 
estimados indicam que uma variação de $1 \%$ na taxa de câmbio real efetiva gera aumento entre $0,012 \%$ e $0,019 \%$ na participação do VTI sobre o PIB estadual, o que indica a importância de um câmbio competitivo (depreciado) para a geração de valor adicionado pela indústria de transformação.

Tabela 4 Resultados para variável dependente VA Indústria (estimações por EA)

\begin{tabular}{lrrrrr}
\hline Modelos & $\mathbf{1}$ & $\mathbf{2}$ & $\mathbf{3}$ & $\mathbf{4}$ \\
\hline TCREF & ${ }^{*} 0.0173968$ & ${ }^{*} 0.0120571$ & ${ }^{* * *} 0.0180442$ & ${ }^{* * *} 0.0188509$ \\
\hline Erros robustos & $(0.0100642)$ & $(0.009196)$ & $(0.005767)$ & $(0.0059778)$ \\
\hline IPCOM & & ${ }^{*}-0.2024552$ & ${ }^{* * *}-0.1996443$ & ${ }^{* * *}-0.1816446$ \\
\hline Erros robustos & $(0.1111093)$ & $(0.0370056)$ & $(0.0378188)$ \\
\hline JUROS & & & -0.0151479 & -0.0136807 \\
\hline Erros robustos & & & $(0.0186747)$ & $(0.0189143)$ \\
\hline ABERT & & & & ${ }^{* * *} 0.0782895$ \\
\hline Erros robustos & $* * * 0.3786578$ & $* * * 0.3588805$ & ${ }^{* * *} 0.3528578$ & ${ }^{* * *} 0.3127394$ \\
\hline PIBESTADUAL & $(0.1079211)$ & $(0.1073496)$ & $(0.0284983)$ & $(0.0293541)$ \\
\hline Erros robustos & 0.0895632 & 0.0776269 & 0.0662647 & 0.0414322 \\
\hline DPIBPERCAPITA & $(0.0958419)$ & $(0.0882357)$ & $(0.0848163)$ & $(0.0829992)$ \\
\hline Erros robustos & $* * 0.3764817$ & -0.2100987 & ${ }^{* * *}-0.1741297$ & ${ }^{* * *}-0.1528293$ \\
\hline DCRISE2008 & $(0.176495)$ & $(0.1943527)$ & $(0.0302672)$ & $(0.0311813)$ \\
\hline Erros robustos & 0.9972 & 1.0000 & 0.1353 & 0.1094 \\
\hline Prob. Teste de Hausman & & & &
\end{tabular}

Fonte: Elaboração própria a partir dos resultados gerados pelo software Stata 13.

Nota: ${ }^{*},{ }^{* *} e^{* * *}$ indicam significância estatística a 10\%,5\% e 1\%, respectivamente.

As evidências para os preços das commodities (IPCOM) também possuem o sinal negativo esperado e significância estatística em todos os modelos. Nesse caso, uma variação de $1 \%$ nos preços daqueles bens gera redução entre 0,181\% e 0,202\% no valor adicionado pela indústria de transformação no $\mathrm{PIB}$ estadual. Isso sugere que o contexto de altos preços internacionais dos produtos primários não se mostra favorável ao dinamismo dos setores industriais, sinalizando ocorrência de desindustrialização via doença holandesa.

A taxa de juros real (JUROS) apresenta o sinal negativo esperado, o que prejudica o investimento na atividade industrial, porém não obteve significância estatística. Já o grau de abertura de produtos manufaturados (ABERT) possui sinal positivo e é estatisticamente significante, indicando que a abertura comercial favorece a atividade industrial. Esse resultado se 
justifica pelo fato de os estados brasileiros serem importadores de máquinas e equipamentos industriais. Assim, passam a adicionar maior quantidade de valor por meio de importações de insumos, o que, de certa forma, também contribui para a desindustrialização.

Entre as variáveis de controle, destaca-se o PIB estadual, que apresenta sinal positivo e significância estatística em todos os modelos, denotando que quanto maior o estado (em montantes financeiros), maior será o aumento da participação do VTI no PIB estadual. A variável PIB per capita possui sinal positivo, porém sem significância estatística. Ou seja, as diferenças de renda entre os estados não se mostram relevantes na adição de valor pela indústria de transformação ao PIB. Já a variável referente à crise de 2008 apresenta sinal negativo e é significante estatisticamente, exceto na segunda especificação do modelo, indicando prejuízo da crise internacional na geração de valor pela indústria estadual.

Tabela 5 Resultados para variável dependente Emprego Indústria (estimações por EA)

\begin{tabular}{lr|r|r|r}
\hline Modelos & $\mathbf{1}$ & $\mathbf{2}$ & $\mathbf{3}$ & $\mathbf{4}$ \\
\hline TCREF & 0.0014523 & -0.0016987 & 0.0030693 & 0.0028657 \\
\hline Erros robustos & $(0.0054222)$ & $(0.0055822)$ & $(0.0029829)$ & $(0.0029983)$ \\
\hline IPCOM & & ${ }^{* *}-0.12601$ & ${ }^{*}-0.0351694$ & -0.0254626 \\
\hline Erros robustos & & $(0.0580082)$ & $(0.019259)$ & $(0.0193131)$ \\
\hline JUROS & & & 0.0099991 & 0.0105072 \\
\hline Erros robustos & & & $(0.0097227)$ & $(0.0096697)$ \\
\hline ABERT & & & & $* * 0.0390425$ \\
\hline Erros robustos & & & & $(0.0096728)$ \\
\hline PIBESTADUAL & 0.1328068 & 0.1092853 & ${ }^{* *} 0.0383394$ & 0.0162575 \\
\hline Erros robustos & $(0.1012236)$ & $(0.0997233)$ & $(0.0152333)$ & $(0.0160438)$ \\
\hline DPIBPERCAPITA & $* * *-0.1712$ & ${ }^{* * *}-0.1780$ & ${ }^{* * *}-0.1350109$ & $* * *-0.123320$ \\
\hline Erros robustos & $(0.0431224)$ & $(0.0435056)$ & $(0.0448674)$ & $(0.0444249)$ \\
\hline DCRISE2008 & ${ }^{*}-0.357418$ & -0.2320239 & ${ }^{* * *}-0.0403924$ & $*-0.0298272$ \\
\hline Erros robustos & $(0.1946158)$ & $(0.1785736)$ & $(0.0156719)$ & $(0.0156766)$ \\
\hline Prob. Teste de Hausman & 0.9835 & 0.9194 & 0.3486 & 0.2757 \\
\hline F & & &
\end{tabular}

Fonte: Elaboração própria a partir dos resultados gerados pelo software Stata 13.

Nota: ${ }^{*},{ }^{* *} e^{* * *}$ indicam significância estatística a 10\%, 5\% e 1\%, respectivamente.

As evidências para a variável dependente Emprego indústria, expostas na Tabela 5, indicam que a taxa de câmbio real efetiva (TCREF) mantém si- 
nal positivo, exceto na especificação 2 , mas perde significância estatística em todos os modelos. Isso sugere que o contexto cambial não se mostra relevante para geração de emprego pela indústria de transformação nos estados brasileiros.

Os preços das commodities (IPCOM) mantêm o sinal negativo esperado, com significância estatística (exceto na especificação 3). Os coeficientes estimados indicam que uma variação de $1 \%$ nos preços das commodities gera redução entre $0,035 \%$ e $0,126 \%$ na geração de emprego pela indústria de transformação estadual, o que pode significar transferência de recursos produtivos para os setores primários.

No caso da taxa de juros (JUROS), os coeficientes não apresentaram o sinal negativo esperado, porém os resultados não são estatisticamente significativos. Novamente, o coeficiente obtido para o grau de abertura dos produtos manufaturados (ABERT) é positivo e possui significância estatística. Tal evidência sugere que o processo de abertura comercial facilita as importações de máquinas e equipamentos, com benefício à geração de empregos pela atividade industrial.

Quanto às demais variáveis de controle, o PIB estadual mantém o sinal positivo, embora com significância estatística apenas na segunda especificação. Já o PIB per capita é estatisticamente significativo em todos os modelos e apresenta sinal negativo, indicando que a indústria de transformação nos estados com maiores rendas per capita (graus de desenvolvimento) perde relevância na geração de emprego. Isso pode ser atrelado ao fato de que tais estados podem adotar tecnologias poupadoras de mão de obra, com aumento de produtividade do trabalho. A dummy Crise de 2008 apresenta sinal negativo, e é estatisticamente significativa (exceto na segunda especificação), indicando que a crise internacional impacta na geração de emprego pela indústria de transformação nos diversos estados. Cabe reforçar que as estimações para o emprego são passíveis de crítica como forma de se avaliar um possível processo desindustrializante, visto que o emprego pode ser afetado pelo aumento de produtividade dos trabalhadores, e não por um processo estrito de desmantelamento da estrutura produtiva industrial.

Em síntese, os efeitos das variáveis taxa de câmbio real efetiva e preços das commodities sugerem um processo de desindustrialização em curso pela via da doença holandesa, conforme apontam os trabalhos de Bresser-Pereira e Marconi (2008) e Oreiro e Feijó (2010). Apesar de o resultado da 
proxy para o grau de abertura comercial não ter sido negativo, acredita-se que ele tenha sido influenciado pela pauta de importações dos estados, baseada em insumos industriais, mostrando outra face do problema. Ou seja, os efeitos da abertura comercial insinuam que a geração de valor agregado nos produtos brasileiros se dá no exterior por meio da importação de insumos para produção, e não propriamente por um processo de substituição de importações de bens industrializados finais.

Dessa forma, as evidências obtidas sugerem que o conceito abordado de desindustrialização negativa, ou seja, de perda de participação industrial relativamente às atividades primárias em termos de geração de valor adicionado ou de emprego, pode ser utilizado para explicar a dinâmica da indústria de transformação no âmbito dos estados brasileiros. As variáveis analisadas demonstram que há um contexto favorável aos produtos primários, o que, em última instância, pode ocasionar especialização regressiva da estrutura produtiva e exportadora da economia em produtos primários em detrimento das atividades industriais.

\section{Considerações finais}

Este artigo investigou a hipótese de desindustrialização no Brasil baseando-se em dados para os estados brasileiros no período 1996 a 2014. A revisão da literatura que discute o problema nos estados individuais demonstrou que ainda há espaço para tratamento empírico do tema, pois os estudos existentes tornam os resultados sujeitos à amostra, à metodologia e ao período temporal analisados. Contudo, em linhas gerais, há o argumento de que a atividade industrial no Brasil e em algumas de suas Unidades Federativas está declinando.

A análise dos indicadores tradicionalmente utilizados para avaliar desindustrialização revela que, embora a participação do VTI no PIB tenha aumentado em vários estados, os montantes não foram significativos para influenciar positivamente os resultados nacionais. Ainda, os resultados na região Sudeste, cuja indústria de transformação é mais representativa, foram negativos, o que implica possível processo de desindustrialização nessa região, ou, ainda, descentralização da indústria. Por outro lado, boa parte dos estados perdeu participação industrial no emprego total. Contudo, esse resultado pode ser afetado por ganhos de produtividade do traba- 
lho, o que dificulta a confirmação da hipótese de desindustrialização pela análise do emprego. Por fim, os dados da inserção comercial mostraram perda de relevância dos bens manufaturados frente ao avanço dos produtos primários nas exportações de diversos estados, sinalizando desindustrialização via doença holandesa.

A partir dessas evidências preliminares, foram estimados modelos em painel por Efeitos Aleatórios, conforme o teste de Hausman. Nos resultados para a participação do VTI no PIB estadual, observou-se a importância de uma taxa de câmbio real competitiva (depreciada) para beneficiar a produção de manufaturados, evitando a transferência de recursos produtivos para os setores primários. Os elevados preços internacionais das commodities também parecem prejudicar a geração de valor pela indústria de transformação. No caso do emprego estadual, embora o contexto cambial não tenha sido significativo, os preços das commodities contribuíram para a menor relevância da indústria de transformação em criar postos de traba1ho. Tais evidências sinalizam desindustrialização associada a um processo de doença holandesa.

Quanto aos efeitos das políticas econômicas, as elevadas taxas de juros reais vigentes na economia não se mostraram relevantes para explicar a capacidade da indústria de transformação em gerar produto e emprego. A abertura comercial foi significativa em afetar o valor adicionado e o emprego industrial pela capacidade de importar de forma mais barata insumos utilizados na produção de manufaturados, mais do que pela substituição de produção interna por bens finais importados. Isso tende a refletir maior adição de valor com conteúdo importado, o que prejudica a densidade da cadeia de produção dos bens industriais.

A lição geral deste estudo é a de que existem elementos que advertem para a ocorrência de um processo de desindustrialização negativa nos estados brasileiros. A perda de relevância da atividade industrial em alguns estados (e no país) parece alinhada aos fatores que promovem a reprimarização da pauta exportadora. Assim, devido ao importante papel da indústria como sustentadora do crescimento no longo prazo, os estados devem pensar estratégias que visem estimular a recuperação da atividade industrial, de forma que se atenue o contexto de concentração nos setores de produtos primários, garantindo, assim, uma reversão da perda de contribuição relativa da indústria de transformação no produto e no emprego. 


\section{Referências}

ALMEIDA, T. R. C.; SOUZA, C. C. A. Evolução da estrutura industrial de Minas Gerais no período 1960-2010: uma análise frente aos demais estados da Federação. XVI SEMINÁRIO SOBRE A ECONOMIA MINEIRA EM DIAMANTINA. Diamantina, 2014. Anais...

ARRIEL, M. F.; CASTRO, S. D. O perfil produtivo da indústria Goiana. Conjuntura Econômica Goiana, Goiânia, SEPLAN - Secretaria do Planejamento e Desenvolvimento, Boletim Trimestral, n. 15, 2010.

BARBOSA, W.; CARMO, A. S. S.; RAIHER, A. P. Existe desindustrialização no Estado do Paraná? Um teste empírico para o período de 1996 a 2012. Informe Gepec, Toledo, v. 19, n. 1, p. 55-79, jan./jun. 2015.

BCB. Banco Central do Brasil. Economia e Finanças. Séries Temporais. Disponível em: $<$ http://www4.bcb.gov.br/?SERIESTEMP>. Acesso em: nov. 2015.

BOTELHO, M. dos R. A.; SOUSA, G. F.; AVELLAR, A. P. M. A incidência desigual do processo de desindustrialização nos estados brasileiros. XVI SEMINÁRIO SOBRE A ECONOMIA MINEIRA DE DIAMANTINA. Diamantina, 2014. Anais...

BRESSER-PEREIRA, L. C. Doença holandesa e sua neutralização: uma abordagem ricardiana. Revista de Economia Política, n. 28, p. 47-71. 2007.

BRESSER-PEREIRA, L. C.; MARCONI, N. Existe doença holandesa no Brasil? IV FÓRUM DE ECONOMIA DA FUNDAÇÃO GETÚlIO VARGAS. Março, 2008. Disponível em: $<$ http://www.bresserpereira.org.br>. Acesso em: set. 2015.

CAÇADOR, S. B.; GRASSI, R. A. A evolução recente da economia do Espírito Santo: um estado desenvolvido e periférico? XXXVII ENCONTRO NACIONAL DE ECONOMIA. Foz do Iguaçu, dezembro, 2009. Anais...

CANO, W. A desindustrialização no Brasil. Economia e Sociedade, Campinas, vol: 21, Número Especial, p. 831-851, dez. 2012.

CARIO, S. A. F.; NICOLAU, J. A.; SEABRA, F.; BITTENCOURT, P. Processo de desindustrialização em Santa Catarina. Florianópolis: Federação das Indústrias do Estado de Santa Catarina (FIESC), Núcleo de Economia Industrial e da Tecnologia - Universidade Federal de Santa Catarina (UFSC), 2013.

CARVALHO, L.; KUPFER, D. A transição estrutural da indústria brasileira: da diversificação para a especialização. XXXV ENCONTRO NACIONAL DE ECONOMIA DA ANPEC, Recife, 2007. Anais...

CASTILHOS, C. C.; CALANDRO, M. L.; CAMPOS, S. H. Reestruturação da indústria gaúcha sob a ótica da reordenação da economia mundial. O movimento da produção. (Três décadas de economia gaúcha, v.2). 2010.

CAVALIERI, H.; CARIO, S. A. F.; FERNANDES, R. L. Estrutura industrial brasileira e de Santa Catarina: alguns indícios de desindustrialização. Indic. Econ. FEE, Porto Alegre, v. 40, n. 3, p. 81-104, 2013.

CRUZ, B. O.; SANTOS, I. R. S. Dinâmica do emprego industrial no Brasil entre 1990 e 2009: uma visão regional da desindustrialização. TD 1673. IPEA. Rio de Janeiro, nov. 2011. 
FERREIRA, J. S. W. São Paulo: o Mito da Cidade-Global. 2003. 336f. Tese (Doutorado) - Faculdade de Arquitetura e Urbanismo, Universidade de São Paulo, São Paulo, 2003.

HSIAO, C. Panel Data Analysis - Advantages and Challenges, IEPR Working Papers 06.49, Institute of Economic Policy Research (IEPR), 2006.

IBGE. Instituto Brasileiro de Geografia e Estatística. Indicadores. Contas Nacionais. Disponível em: <http://www.ibge.gov.br/home/estatistica/indicadores/pib/defaultcnt.shtm>. Acesso em: nov. 2015.

IMF. International Monetary Fund. Disponível em: <https://www.imf.org/en/Data $>$. Acesso em: mai. 2016.

KALDOR, N. Causes of the slow rate of economic growth of the United Kingdom. London: Cambridge University Press, 1966.

MAGALHÃES M. A.; TOSCANO, V. N. Vocação para exportar: uma avaliação retrospectiva dos padrões de comércio exterior do estado do Espírito Santo (1996-2010). Vitória, ES: Instituto Jones dos Santos Neves, 2011.

MDIC. Ministério do Desenvolvimento, Indústria e Comércio Exterior. Estatísticas do Comércio Exterior. Disponível em: <http://www.mdic.gov.br>. Acesso em: nov. 2015.

MONTEIRO, F. D. S. C.; LIMA, J. P. R. Desindustrialização regional no Brasil. Nova Economia, v.27, n.2, p.247-293, 2017.

OREIRO, J. L.; FEIJÓ, C. A. Desindustrialização: conceituação, causas, efeitos e o caso brasileiro. Revista de Economia Politica, v. 30, n. 2 (118), pp. 219-232, abr./jun. 2010.

PALMA, J. G. Quatro fontes de "desindustrialização" e um novo conceito de "doença holandesa". CONFERÊNCIA DE INDUSTRIALIZAÇÃO, DESINDUSTRIALIZAÇÃO E DESENVOLVIMENTO, FIESP e IEDI, (Org.). São Paulo: Centro Cultural da FIESP, ago. 2005.

REZENDE, F. A. E.; SANTOS, F. Desindustrialização, rearranjo industrial e desemprego no Brasil. O caso do ABC paulista. Revista Eletrônica, ano 1, n. 1, p. 31-34. 2007.

ROSENDO, R. C.; BRITTO, J. Evolução da densidade industrial do estado do Rio de Janeiro: análise comparativa com os estados do Sudeste brasileiro - 2000/2005. 39. ENCONTRO NACIONAL DE ECONOMIA. Foz do Iguaçu, dezembro. 2011. Anais...

ROWTHORN, R.; RAMASWAMY, R. Deindustrialization: causes and implications. Staff Paper of International Monetary Fund, WP/97/42. Apr. 1997.

ROWTHORN, R.; WELLS, J. R. De-Industrialization and Foreign Trade. Cambridge: Cambridge University Press. 1987.

SABOIA, J. Descentralização industrial no Brasil na década de noventa: um processo dinâmico e diferenciado regionalmente. Nova Economia, v. 11, n. 2, p. 85-122, dez. 2001.

SCATOLIN, F. D.; CRUZ, M. J. V.; PORCILE, G.; NAKABASHI, L. Desindustrialização? uma análise comparativa entre Brasil e Paraná. Porto Alegre, Indic. Econ. FEE, v. 35, n. 1, p. 105-120, 2007.

SOBRAL, B. L. B. A Falácia da "inflexão econômica positiva": algumas características da desindustrialização fluminense e do "vazio produtivo" em sua periferia metropolitana. $\mathrm{Ca}$ dernos do Desenvolvimento Fluminense, Rio de Janeiro, n. 1, fev. 2013.

SOUSA, G. F; CARDOZO, S. A. Estrutura produtiva de Minas Gerais e participação estadual 
na produção industrial nacional nos anos 2000. Revista Horizonte Científico, v. 7, n. 1, set. 2013.

TEIXEIRA, F. W.; RODOLFO, F. Trajetória recente do setor industrial catarinense: uma análise com base nos dados da produção física. Revista NECAT, Florianópolis, ano 1, n. 1, p. 22-30, 2012.

TREGENNA, F. Characterizing deindustrialization: an analysis of changes in manufacturing employment and output internationally. Cambridge Journal of Economics, v. 33. p. 433-466, 2009.

VERÍSSIMO, M. P.; ARAÚJO, S. C. Perfil industrial de Minas Gerais e a hipótese de desindustrialização estadual. Rev. Bras. Inov., Campinas (SP), 15 (1), p. 113-138, jan./jun. 2016.

VIEIRA, F. V.; HADDAD, E. A.; AZZONI, C. R. Export performance of Brazilian states to Mercosul and non-Mercosul partners. Latin American Business Review, 15:3-4, 253-267, 2014.

WASQUES, R. N. O fenômeno da desindustrialização: uma análise do caso paranaense no período 1990-2010. Economia \& Tecnologia. Curitiba, v. 8, n. 1, p. 67-76, 2012.

\section{Sobre os autores}

Iago Emidio Lutz de Souza - iagolutz@hotmail.com

(Universidade Federal de Uberlândia, Uberlândia, Minas Gerais, Brasil.

ORCID: https://orcid.org/0000-0002-5183-6866.

Michele Polline Veríssimo - micheleverissimo@ufu.br

Universidade Federal de Uberlândia, Uberlândia, Minas Gerais, Brasil.

ORCID: https://orcid.org/0000-0002-8436-2134.

Os autores agradecem à Fundação de Amparo à Pesquisa do Estado de Minas Gerais (FAPEMIG) e ao Conselho Nacional de Desenvolvimento Científico e Tecnológico (CNPq) pelo apoio financeiro à realização desta pesquisa.

\section{Sobre 0 artigo}

Recebido em 26 de maio de 2017. Aprovado em 09 de setembro de 2017. 